\title{
Digital Platform for Distance and On-site Engineering Learning
}

\author{
Ravil S. Zagidullin ${ }^{1 *}$ and Alexander S. Chernikov ${ }^{1}$ \\ ${ }^{1}$ Bauman Moscow State Technical University, 2nd Baumanskaya str., 5/1, 105005, Moscow, Russia
}

\begin{abstract}
This paper considers the experience of elaborating and implementing an on-site and distance practical study of electronics and circuit Engineering in the educational process. Authors provide possibilities of using both distance and on-site laboratory practical works. The paper includes recommendations for choosing hardware-based solutions. It also shows the implemented version of remote user access to individual data of laboratory research, which provides individualization of obtaining experiment data, when using FTP means of data transfer. Data from a remote experiment, in this case, is completely closed from access by third parties, while the teacher is given access to data from experimental studies of all students. The solution was implemented in the LabVIEW platform, as well as the general solution for implementing software access to a remote bench. The paper describes the main elements of the hardware and software system, shows its structure and presents the work examples. It also notes the integration of the LabVIEW software and the Multisim circuit and system simulating platform, which serves to improve the quality of specialists training during distance and on-site practical works. The authors consider several options for conducting distance and on-site laboratory practical works when preparing laboratory layouts for use. The work of students, both distance and on-site, as well as teacher-student interaction, is organized using the MOODLE platform.
\end{abstract}

\section{Introduction}

Distance learning is rapidly developing. Nowadays, courses in many Humanities and Sciences related to IT technologies have been implemented within the framework of distance learning programs. However, the organization of distance learning in technical Sciences has encountered some problems. There are very few remote engineering courses.

However, laboratory classes and practical studies are an important part of students' training, especially when teaching engineering. Distance learning provides an opportunity to study individually, regardless of the place and time, to receive education continuously and according to an individual program, provides an individual learning path for each student. The student can choose the sequence of study subjects and the pace of work. Standard distance learning systems, including the MOODLE system, allow you to provide information in the form of lectures, seminars, videos, conduct tutorials and check the

* Corresponding author: zag@bmstu.ru 
information acquisition, track attendance, keep statistics, evaluate work at the end of classes, and accumulate results about courses completed.

It is extremely important to develop a laboratory base consisting of real equipment and computerized laboratories. The creation of a modern laboratory base for the educational process and applied scientific research will allow training of highly qualified students at a whole new level and in the interests of enterprises. But we should not omit the issue of using already developed solutions based on old equipment and measuring devices upgraded with modern computer control and data collection capabilities. In these laboratory classes, it is extremely important to use methods of simulation of the developed and used solutions and computer automation of experimental research [1-2]. In these laboratory works, it is important to show the relationship between the simulation of complex circuit solutions and experimental solutions, associated with them. At the same time, it is essential to maintain an integrated approach to set specific tasks.

\section{Software and hardware base of the laboratory course}

In BMSTU there are remote access laboratories (via a local network or the Internet), as well as the possibility of automating laboratory classes using local benches. The creation of a modern laboratory base for the educational process and applied scientific research will allow training of highly qualified students at a whole new level and in the interests of enterprises. While creating laboratory courses, the development of digital networks, computer and Internet technologies allows

- Using the latest laboratory base and quickly reconfigure existing benches;

- Upgrading existing and outdated laboratory bases;

- Introducing new approaches to research through the creation of automated laboratory courses.

The LabVIEW (Laboratory Virtual Instrument Engineering Workbench) platform is used as a tool for developing control systems and data collection [3]. The LabVIEW platform provides great opportunities for building reconfigurable laboratory benches and for implementing data exchange over TCP/IP networks. It allows the teacher to reconfigure laboratory benches for the class and allows students to exchange experimental data obtained at the benches via TCP / IP networks. A computer equipped with measurement and control hardware and LabVIEW software allows automating the process of physical research and elaboration.

BMSTU has a University licensed version of LabVIEW for installation on all University computers. Data collection tools (industrial computers based on PXI solutions, ELVIS devices, myDAQ Arduino controllers) make it possible to implement almost unlimited options for laboratory research [4]. The object of measurement and research is managed both through a program on the local computer and through the Internet. The LabVIEW Web server generates an HTML document in the dialog mode and publishes images of the computer front panel in the Network by integrating them in a Web page.

With this approach, it is sufficient to have a single multifunctional laboratory bench connected (for example, using the computer network) to the students' workplaces. Personal computers in the classroom are usually used as working places for laboratory research or practical studies. At the same time, individual access to the laboratory complex is provided in the time-sharing mode to provide the complete impression that the student is one to one with the experimental setup to perform his task. Individual access to the laboratory facilities takes place in the time-sharing mode according to the principle: one working place - one user. To provide laboratory and practical works for a group of students, it is sufficient to 
have a single automated multifunctional laboratory facility connected to the students' workplaces. When planning the structure and content of laboratory courses and practical works, it should be assumed that laboratory research and practical works have different leading didactic goals, although they practically have the same workload.

When performing practical work, the student can interact not only with real devices and objects but also with their mathematical models. This does not exclude interaction with real objects and measuring devices at the next stage of the study. The Multisim software product, which is very popular in Russian higher education institutions, serves this purpose. Multisim can integrate with real physical equipment for designing and developing analog and digital electronic circuits and Multisim systems [5]. The integration makes it possible to develop printed circuit boards (using Ultiboard module), program microcontrollers and microprocessors and emulate their work with various additional devices: RAM, ROM, keyboard, as well as graphic and alphanumeric liquid crystal displays (MCU Module), conduct physical experiments, collect data and test the created product.

The Multisim platform allows performing experiments of any complexity, replacing circuit components easily, changing their values, predicting and displaying obtained results. Taking advantage of this opportunity, students will be able to go through all the stages of development and creation of a real electronic product - from the development of its schematic diagram to testing the final product. Designed schemes can be tested quickly and easily. They also can be modified, which can be easily implemented physically further. Thus, revealing physical faults during the manufacturing process will be minimal. One of the most interesting features of the latest versions of Multisim is its integration with real physical hardware and the possibility of experimental verification of a theoretical study.

Expanding the scope of LabVIEW and Multisim, National Instruments released a special Toolkit - LabVIEW Multisim Connectivity Toolkit. The LabVIEW Multisim Connectivity Toolkit allows you to manage the Multisim core via the Multisim API. The joint use of Multisim and LabVIEW allows not only performing laboratory course or conduct an experiment but also to implement a full cycle of hardware and software module design [6-7]. Multisim includes the Ultiboard program unit - an easy-to-use and intuitive PCB development platform. The circuit created in Multisim is passed to Ultiboard to get a ready-made, routed $\mathrm{PCB}$. The MCU unit, also included in the Multisim platform, allows you to add a SPICE-emulated integrated circuit microcontroller to the circuit analysis and program it in $\mathrm{C}$ or Assembler while in the Multisim. This feature allows teaching students to work with Intel/Atmel 8051/8052 and Microchip PIC16F84a microcontrollers. Besides, the Multisim MCU unit allows emulating the operation of the microprocessor and various additional devices: RAM, ROM, keyboard, as well as graphic and alphanumeric liquid crystal displays. All these devices are part of the Multisim component database, and it is possible to supplement the database.

A computer measuring system is assembled from various hardware and software components, such as ELVIS and myDAQ by National Instruments [8-9]. The myDAQ and ELVIS platforms are closely integrated with the Multisim software, which allows comparing the result of simulation a circuit solution with a physical solution implemented on a breadboard. The Elvis unified laboratory station is used as a set of virtual measuring instruments for the university laboratory. The compact myDAQ hardware module, connected to a computer, allows you to represent a set of 8 software-configurable measuring devices (digital multimeter, oscilloscope, function generator, frequency response/frequency response analyzer, dynamic signal analyzer, random signal generator, digital recorder, and reader) and conduct classes anywhere and at any time. The display of control elements is performed on the personal computer screen. 
LabVIEW can be used on computers running various operating systems: Windows, macOS, Linux, Solaris, and HP-UX. Network applications of the LabVIEW platform allow turning a local laboratory bench into a bench that can be managed remotely via the Internet.

In the laboratory with the LabVIEW software and the corresponding data collection equipment, you can effectively use not only the new laboratory base but also upgrade the old one. Moreover, you can quickly reconfigure the laboratory benches and combine the features of distance education and traditional engineering studies technologies.

It is important to note that the carrying-out of the practical works is required to provide working not only in the framework of remote access and open education but also with traditional face-to-face technologies of the educational process, Fig. 1. To perform this, there are several options for generation a hardware solution in such a laboratory:

- on-site practical work at the laboratory bench;

- distance practical work with access to the laboratory equipment via the local network;

- distance practical work with access to the laboratory equipment via the Internet.

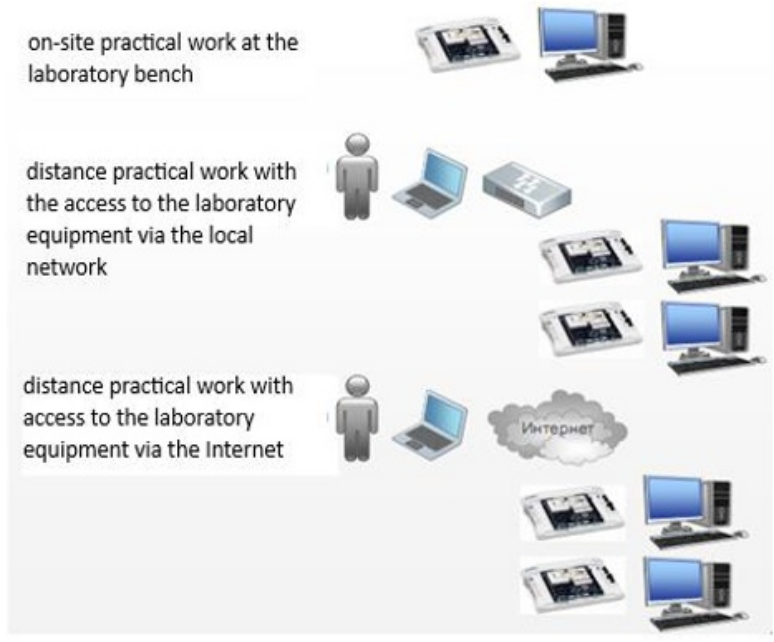

Fig. 1. Options for building a hardware solution.

ELVIS II and myDAQ hardware systems, originally designed to work in the LabVIEW, proved to be appropriate for practical works in a laboratory. Programming with the specified hardware solution is initially provided by the software platform. However, if the programmer is qualified enough, it is possible to include in the hardware-software complex third-party hardware devices for data collection and processing, such as ARDUINO. This also keeps the advantages of programming in LabVIEW and budget funds (Fig. 2).
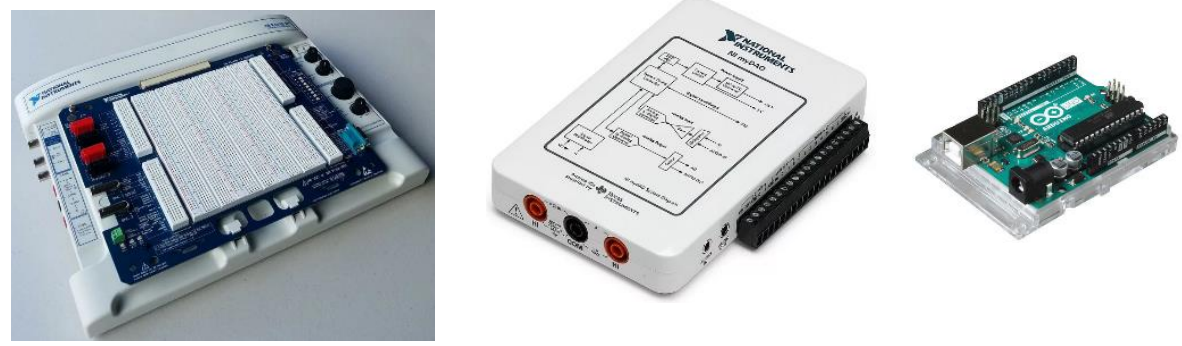

Fig. 2. Hardware systems ELVIS II, myDAQ and ARDUINO. 


\section{Practical work in a laboratory}

During the on-site work in a laboratory students can simulate the circuit diagram using the MULTISIM platform and then assemble circuit solutions on their own, in "manual mode". After that, the assembled layouts are connected to data collection devices (Fig. 3).

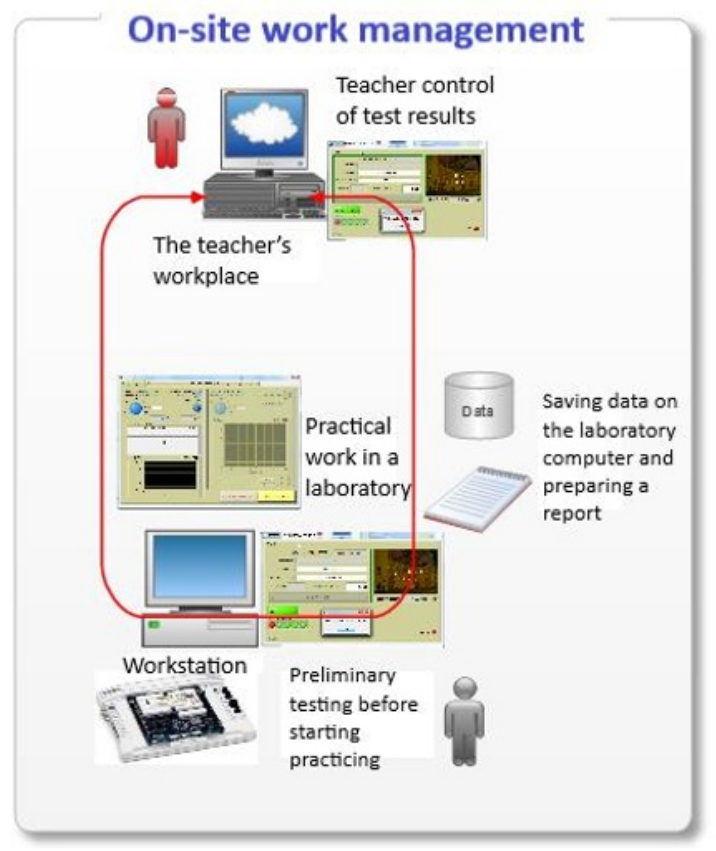

Fig. 3. On-site practical work management.

\section{Distance practical work}

The operation of the remote laboratory in the local network of the University requires access to it from any remote computer using the Internet (Fig. 4).

The security policy provides this operability using DMZ Demilitarized zone technology.

Users of the external network can get into the DMZ computer, which may contain the laboratory bench information, and study it, but the DMZ does not allow access to other data of the University.

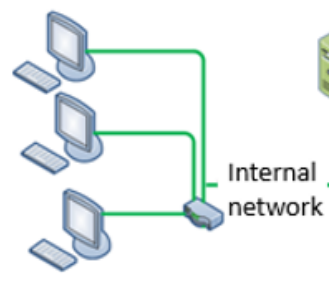

The laboratory of the department, local laboratory network (VPN virtual private network)

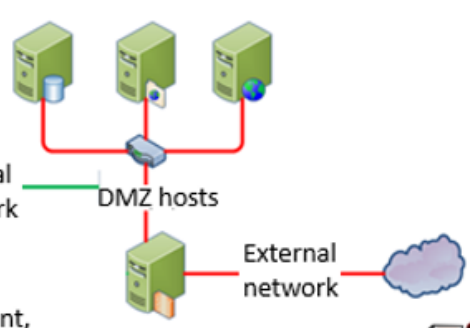

Remote user

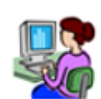

Fig. 4. Distance practical work vial local network. 
For a remote workplace, circuit solutions can be prepared in the form of ready-made modules, assembled in the form of three-dimensional wiring on the breadboards or prepared printed circuit boards. All options are pre-connected to data collection devices and can be used in remote access to the bench (Fig. 5).

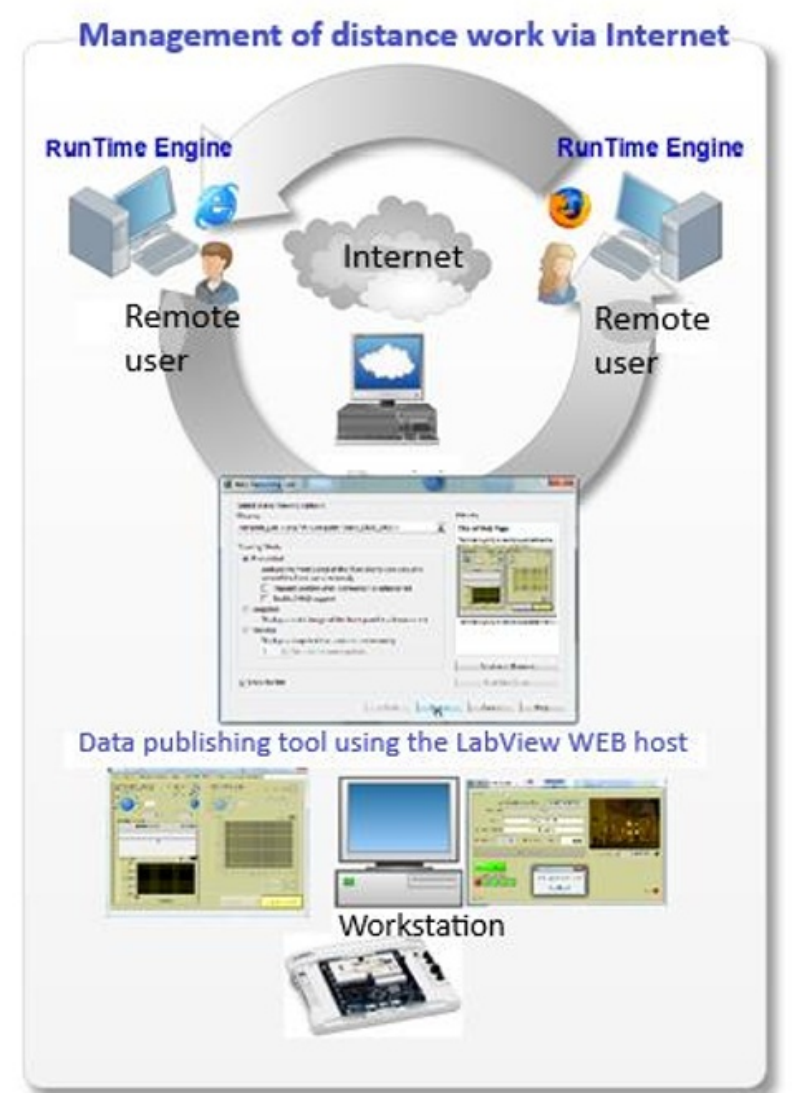

Fig. 5. Distance practical work via Internet.

For example, the myDAQ device allows closely connecting theory and practice due to a set of 8 software-configurable measuring devices, including a digital multimeter, oscilloscope, function generator, amplitude- frequency response and phase-frequency response analyzer, dynamic signal analyzer, random signal generator, digital reader and recorder. In combination with the LabVIEW platform installed on a computer, myDAQ provides a complete solution for studying the basics of engineering, including analog circuitry, the basics of measuring signals from sensors, analog and digital electronics, and the basics of electrical circuit theory. Many universities all over the world are already developing laboratory practical courses for the NI myDAQ platform. Students can program these front control panels themselves and plan the experiment if required. The display of control elements and controls is performed on the personal computer screen Fig. 6. 
Semiconductor diode VAC analysis

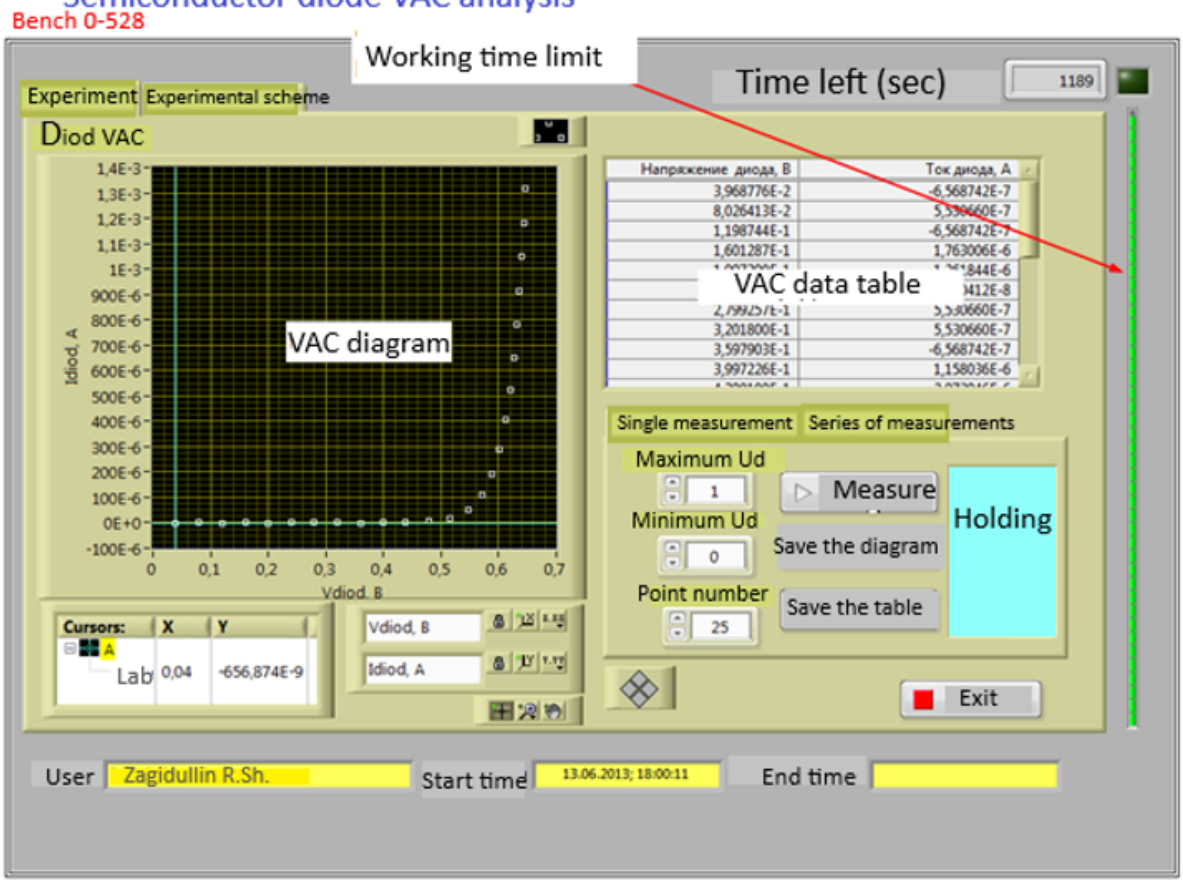

Стена 0-528

Fig. 6. Front control panel of the laboratory bench.

The Moodle platform can be used for work organization work of students both at a remote workplace and in laboratory [10-22]. Any work in this case can be provided with guidelines and multimedia content, Fig. 7. 


\title{
Switch to the practical work N1, N2 at a remote bench
}

Attention: currently the lab benches work in the mode of repeating overloading over every 25 minutes. Thus, if you see the message that the connection is failed, you should wait for 1 minute and try again.

To work at a remote laboratory bench use the Internet Explores and Firefox browsers of version 50.1 or older.

After RTE installation there is no adjustment required for Internet Explorer and usually for Mozilla FireFox as well.

If there are any problems with using Mozilla Firefox browser, add the plug-in folder to its installation directory (usually the direction is C: \Program Files (x86) \Mozilla FireFox \ plugins) .

You can get the folder (its ISO image) using the link.

To start the laboratory work you can follow the link below. Each work has its own link.

\section{Remember:}

One user-one bench, one bench-one work. After finishing the work it is necessary to return it to people!!!

Access to the data storage requires the password "stud2013bmstu", for the log-in "ftpstud" It is very accessible to use the FTP Filezilla communication in addition to the browser. Don't forget that during the practical work the laboratory bench is closed for anyone except the current user, so be attentive and manage your working time. If you are done, give the bench resource to others. You can get the data from the remote bench only after work completion and turning off the bench.

Links to receive the data via FTP protocol.

Data repository saved on the remote laboratory work server is password-protected (the individual access code to the bench)

\section{Electronics, RL1 $2^{\text {nd }}$ year}

\section{Switch to the practical work N1, N2 at a remote bench}

\author{
To work at a remote laboratory bench use the Internet Explores and Firefox browsers of version 50.1 or older. \\ After RTE installation there is no adjustment required for Internet Explorer and usually for Mozilla FireFox as well. \\ If there are any problems with using Mozilla Firefox browser, add the plug-in folder to its installation directory \\ (usually the direction is C: \Program Files (x86) \Mozilla FireFox \plugins) . \\ You can get the folder (its ISO image) using the link. \\ To start the laboratory work you can follow the link below. Each work has its own link.
}

Remember:

One user-one bench, one bench-one work. After finishing the work it is necessary to return it to people!!!

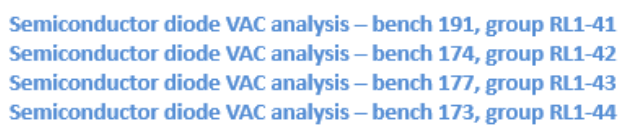

Access to the data storage requires the password "stud2013bmstu", for the log-in "ftpstud" It is very accessible to use the FTP Filezilla communication in addition to the browser.

Don't forget that during the practical work the laboratory bench is closed for anyone except the current user, so be attentive and manage your working time. If you are done, give the bench resource to others. You can get the data from the remote bench only after work completion and turning off the bench. Links to receive the data via FTP protocol.

Data receiving from bench 191

Fig. 7. WEB page fragment of the distance practical work in the MOODLE platform.

This allows improving the quality of preparation for laboratory practical studies, both in the classroom and in the reading room or other convenient workspaces for students. 


\section{Data storage features}

During on-site laboratory studying the student saves the research results on the laboratory computer and can use them for further calculations and data analysis through the computer software. However, when working on the personal computer in remote mode with a remote bench, the student needs to install an additional program Run Time Engine, which is a plugin to the browser. The work progress remains the same as for on-site work in a laboratory. Unfortunately, it should be noted that the browsers upgrading involves a rejection of thirdparty plug-ins. This drawback affects both Firefox and Chrome. Thus, the 49th Firefox version is the latest that can support the RunTime Engine. However, Internet Explorer still saves the day.

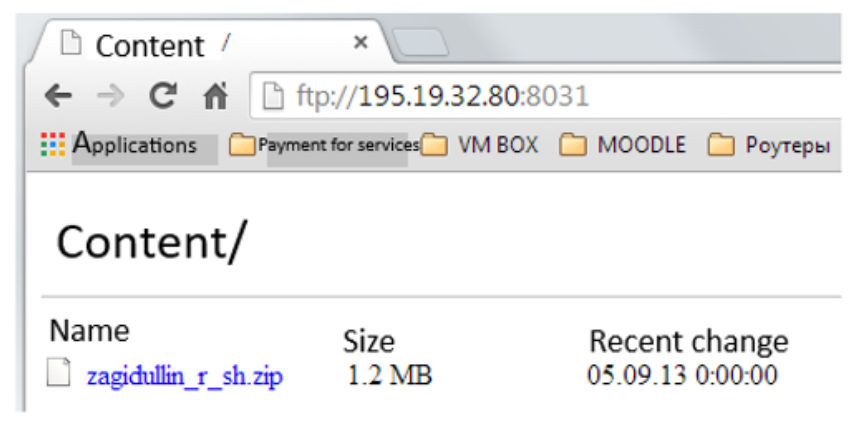

Fig. 8. Access to the data repository of the laboratory practical work in the browser.

In the remote access mode, experimental data is stored only on the server computer of the laboratory bench. However, the student can download the data using FTP data transfer tools to his/ her computer [23-24]. Even though the LabVIEW tools allow data transferring via FTP, the real practice has shown a more convenient way to get the data. This is either the direct use of the browser, or the use of special software, freely distributed programs FileZilla, WinSCP, and their like.

The second problem is that data files stored on the laboratory bench server are freely available to anyone who has access to it. The solution to this problem is that the data is backed up by creating a password during the saving process. The password is the same as for accessing the laboratory bench. Back-up is performed by LabVIEW tools during working and saving data processes.

When receiving data from the laboratory server, the software requests the student's username and password to access the laboratory bench, implementing private access to the results of the experiment. Only the author is allowed extracting the obtained results from the archive, processing the data and including it in the report. Along with saving user data, the software saves the data in a separate directory for the teacher. In this case, the teacher's username and password to the bench act as password protection. Therefore, the teacher, firstly, gets access to the source data and, secondly, controls both the laboratory work progress and the results of the data processing.

\section{Preliminary testing of students}

The software of any type of practical work, distance or on-site, can include control testing (preliminary, introductory control) with educating elements, which is implemented in the LabVIEW software. Besides, the authors proposed a set of programs and support programs 
that allow both preparing these tests and analyzing the results obtained. The programs also perform statistical analysis of not only the test results but also the difficulties in learning individual topics, considering a single group or several groups of students. This helped to improve the quality of students' work and provided teachers a tool for constantly improving the methodological support of the laboratory practical work and improving the content of lectures and way of presenting them.
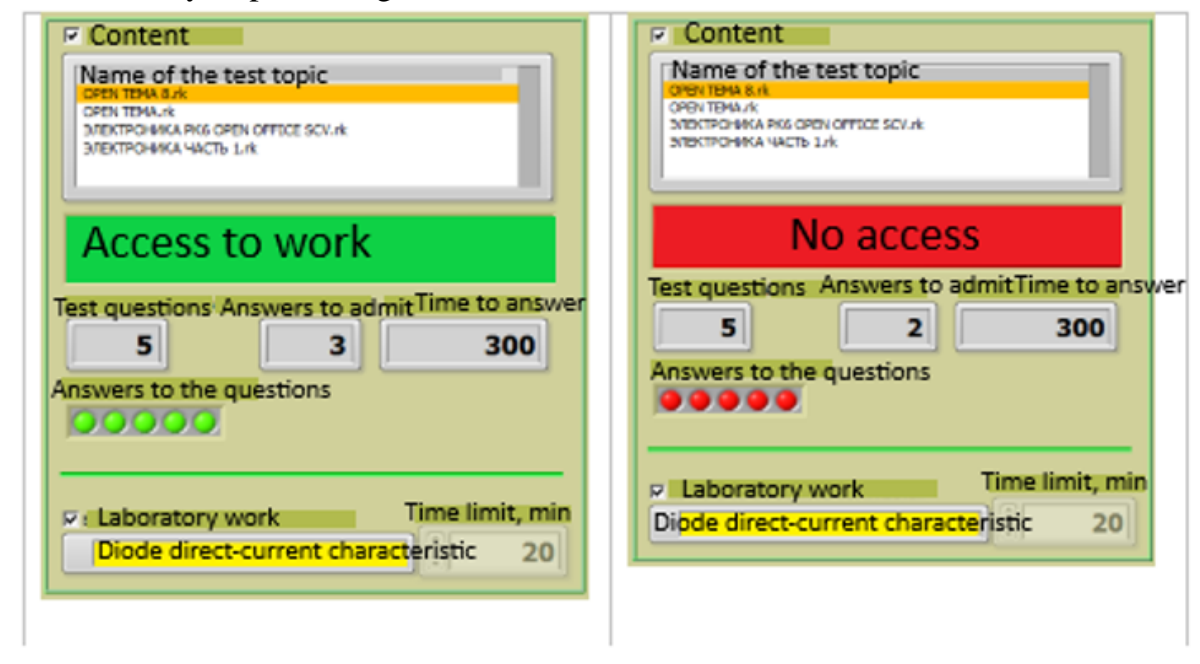

Fig. 9. An example of the practical work preliminary testing.

Using MOODLE with its controlling and testing capabilities has even strengthened the aspect of conducting remote laboratory studies.

\section{Conclusion}

The results of the research allow for the conclusion about the development prospects of this education course. Using unique experimental and technical equipment in remote access allows teaching students up-to-date. Nevertheless, it does not lead to a significant increase in tuition costs in terms of the mass audience. The integration of unique experimental and production equipment and their simulating tools with LMS systems and administrative management systems for the educational process has a bright future.

\section{References}

1. A.J. Swart, Student usage of a learning management system at an open distance learning institute: A case study in electrical engineering, International Journal of Electrical Engineering Education, Vol. 52, pp. 142-154 (2015)

2. Implementation of Industrial Automation Laboratories for E-learning, International Journal of Electrical Engineering Education, Vol. 49, pp. $402-418$ (2012)

3. LabVIEW. Available at: http://www.labview.ru/ (accessed 14.11.2019)

4. R.Sh. Zagidullin, V.Yu. Antipov, Obyedineniye LABVIEW 2009 i MOODLE dlya organizatsii udalennykh laboratornykh rabot na oborudovanii NI PXI [Combination of LABVIEW 2009 and MOODLE for organization of remote laboratory classes using NI PXI equipment], Inzhenernyye. nauchnyye i obrazovatelnyye prilozheniya na baze tekhnologii National Instruments — 2011: Sbornik trudov X mezhdunarodnoy 
nauchno-prakticheskoy konferentsii: [Proc. 10th international scientific and practical conference "Engineering, scientific and educational applications based on National Instruments technology — 2011”], Moscow: DMK-press, pp. 309-310 (2011)

5. NI Multisim. Available at: http://www.ni.com/multisim/ (accessed 14.11.2019).

6. Official website of the Moodle platform. Available at: https://moodle.org (accessed 14.11.2019).

7. Blackboard Learning System (Release 6). (n.d.). Retrieved from http://blackboardsupport.calpoly.edu/content/about/Print/Bb6LearnWP.pdf

8. A. Büchner, Moodle 3 Administration, Birmingham: Packt Publishing (2016)

9. Moodle Docs 2.8. (n.d.). Retrieved from https://docs.moodle.org/28/en/?lang=it

10. A. Gardel, I. Bravo, P.A. Revenga, J.L. Lázaro \& J. García, Implementation of Industrial Automation Laboratories for E-learning, International Journal of Electrical Engineering Education, 49, pp. 402-418 (2012)

11. F. Alam, R.G. Hadgraft, Q. Alam, eLearning: Challenges and Opportunities, F. Alam (Ed.), Using Technology Tools to Innovate Assessment, Reporting, and Teaching Practices in Engineering Education, pp.217 - 226, Hershey: IGI Global (2014)

12. L. Oliveira, N. Vasconcelos, F. Queiroz, J. Queiroz \& H. Hékis, Contribution of Integrated Management Systems to University Management: Case Study of the Federal University of Rio Grande Do Norte, Journal of Social Sciences, 7(3), pp. 415-422 (2011)

13. S. Palahicky, Utilizing Learning Management System (LMS) Tools to Achieve Differentiated Instruction, J. Keengwe \& J.J. Agamba (Eds.), Models for Improving and Optimizing Online and Blended Learning in Higher Education, pp. 12 - 33, Hershey: IGI Global (2014)

14. A. Poncela, A Blended Learning Approach for an Electronic Instrumentation Course, International Journal of Electrical Engineering, 50, pp. 1-1 (2013)

15. P. Radoyska, N. Spasova, Remote FPGA Lab, International Journal of Web-Based Learning and Teaching Technologies (IJWLTT), 7(4), pp. 53-62 (2012)

16. University Management System UMS. (n.d.). Retrieved from http://ampletrails.com/university-management-system-ums.

17. R.S. Zagidullin, A.S. Chernikov, A.A. Chibisov, Integration of MOODLE and ELECTRONIC UNIVERSITY systems at BMSTU, Handbook of Research on Engineering Education in a Global Context, E.V. Smirnova and R.P. Clark.- Hershey, PA: IGI Global, Vol. 2, p.418-429 (2018). DOI: 10.4018/978-1-5225-3395-5

18. R.S. Zagidullin, A.S. Chernikov, Creation of integrated environment at the university for distance and blended education of engineering profile, Nanotechnology: development and applications - XXI Century ISSN 2225-0980, No. 1, pp. 27-39 (2017)

19. R.S. Zagidullin, A.S. Chernikov, Data updating in the MOODLE environment in the remote access mode for a distance laboratory workshop LabVIEW - Multisim, Nanotechnology: development and applications - XXI Century ISSN 2225-0980, No. 1, pp. 40-49 (2017)

20. C. Mwikirize, A.T. Asiimwe, P.I. Musasizi, S.S. Tickodri- Togboa, A. Katumba, J. Butime Makerere. New dimensions in teaching digital electronics: a multimode laboratory utilizing NI ELVIS IITM, LABVIEW AND NI MULTISIM, International Journal of Online and Biomedical Engineering (iJOE) - eISSN: 2626-8493. Vol. 6, Issue 4, November 2010, p.49-54 (2010). doi:10.3991/ijoe.v6i4.1396 
21. Gülden Günay Bulut, M. Emin Şahin, Hasan Güler, An implementation of chaotic circuits with Multisim-LabVIEW, International Advanced Researches and Engineering Journal 02(03), pp. 304-308 (2018)

22. Virtual Instrument Systems in Reality (VISIR) for Remote Wiring and Measurement of Electronic Circuits on Breadboard, IEEE Transactions on Learning Technologies 2013, Vol. 6, pp. 60-72 (2013). DOI Bookmark: 10.1109/TLT.2012.20 